'realities' postulated for race might have alternative explanations.

I suspect that the impact of this book could be the opposite of the authors' intentions. There is much to be said for studying human genetic variability to explore questions of prehistoric ancestry and migration, and to investigate how different human populations respond to medical interventions. But the leap from these to immoderate speculations about the permanence of presentday inequalities is likely to give sceptics even more reason to question racial 'realities'.

Anthropology has a mixed history of dealings with human racial injustice (think of Carleton Coon's view that Africans became human some 200,000 years after white Europeans). The present book, so full of flim-flam and loose speculations, is more likely to re-arm than to deflate sceptics.

Robert N. Proctor is in the Department of History, Pennsylvania State University, University Park,

Pennsylvania 16802, USA.

\section{Plotting the downfall of society}

\section{Historical Dynamics: Why States \\ Rise and Fall \\ by Peter Turchin \\ Princeton University Press: 2003. 264 pp. \\ $£ 22.95, \$ 35$}

\section{Joseph A. Tainter}

In one of history's most extraordinary forecasts, the Greek historian Polybius in the second century $\mathrm{BC}$ predicted the demise of the Roman Empire some 600 years before it fell. Like others of his time, Polybius held a cyclical view of history in which societies, like biological systems, develop through growth, maturity, senescence and death. Polybius might be more celebrated today had he based his prediction on a different theory. Retrospectively, his forecast was no more challenging than anticipating the death of an ox.

Cyclical theories, like the phenomena they postulate, come and go. They have been espoused by historians from Polybius to Oswald Spengler. Serious historians have long held cyclical theories in disrepute, but now they're back, pushed in part by biologists who are accustomed to cycling or pulsing in such systems as predator-prey relationships and ecosystem development. C. S. Holling, for example, has developed a nuanced cyclical view in his 'panarchy' theory, and Kenneth Watt has explored cycling in population, resources and economics.

Beginning with the aphorism that a discipline usually matures only after it has developed mathematical theory, population biologist Peter Turchin attempts in this

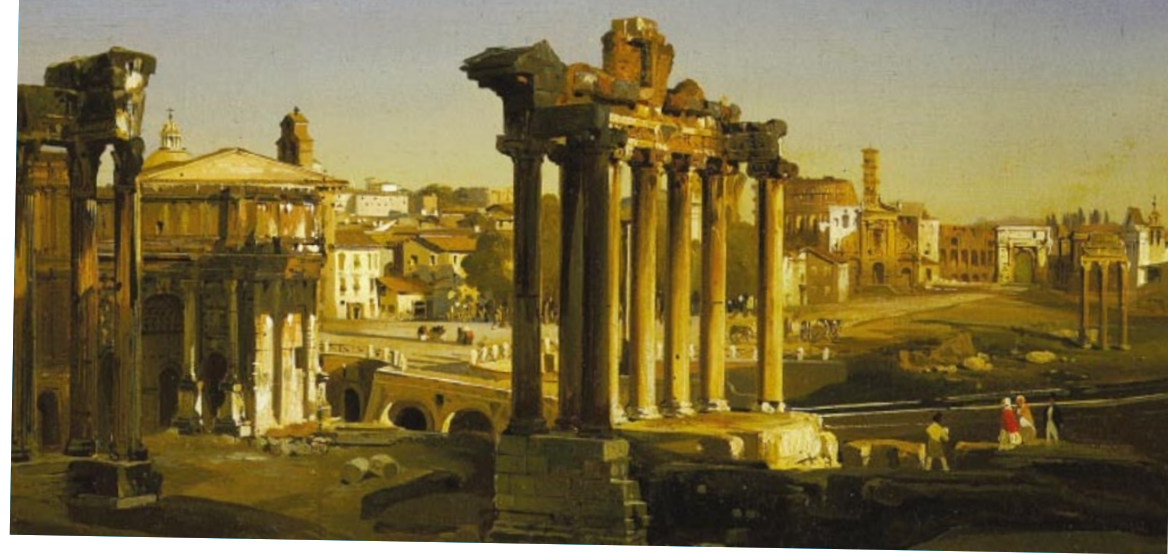

Pride comes before a fall: artist Ippolito Caffi shows how the Roman Empire was left in ruins.

book to develop quantitative cyclical theory in two main areas: territorial expansion and contraction in agrarian states, and population growth and decline in relation to political stability. He has taken care to write for historians: the verbal theories and mathematics are clearly presented, and the work is thoroughly researched and erudite.

Turchin bases his 'mature' approach on the work of the fourteenth-century Arab historian Ibn Khaldun, who sought to explain why desert nomads topple North African dynasties. Ibn Khaldun argued that the founders of dynasties rule well and tax lightly. Succeeding generations, though, develop a taste for luxury, resulting in higher taxation and declining welfare. Late-phase dynasties are challenged by desert nomads who have high degrees of asabiya, defined as collective solidarity or a capacity for collective action. Nomads with asabiya topple dynasties that lack it, starting the cycle anew. Ibn Khaldun perhaps meant his theory as a critique, but Turchin takes it literally. It might be called the 'team spirit' theory of history.

In his 'metaethnic frontier theory,' Turchin proposes that areas where imperial frontiers coincide with major ethnic boundaries function as 'asabiya incubators'. High asabiya allows a peripheral people to expand as an old empire contracts. Turchin builds this idea into quantitative simulations of expansion and contraction in European territorial history from AD 500 to 1900 . The quantification is built on ordinal scaling, judgemental assignment of values, and arbitrary cut-offs.

Like Polybius, Turchin can mimic actual outcomes despite having a dubious social theory. Metaethnic frontier theory is flawed by its primordial assumptions (for example, that ethnic groups are 'quintessential human groups' and that conflict is innate) and by failures of fact and logic. Turchin ignores problems of complexity in large societies, and asymmetrical warfare between states and non-states. States, of course, inculcate something akin to asabiya in their armed forces. Ask soldiers why they fight and they will answer: "For my buddies" — rather like nomads. Asabiya was strangely ineffective during the centuries when North African nomads failed to expel the Carthaginians, Romans, Vandals and Byzantines. And one wonders about the ethnic solidarity of Renaissance armies that were filled with mercenaries, a matter that Turchin ignores when he simulates European territorial changes.

'Demographic-structural theory' builds on Jack Goldstone's excellent work on population growth and state breakdown, and on Turchin's own experience in population biology. This exercise quantifies how political instability and population interact. Unsurprisingly, Turchin's models show that interaction between population dynamics and a state's fiscal health produces cycles of expansion and breakdown.

This theory is on firmer ground than asabiya, but much of the discussion remains simplistic. In his population model, Turchin treats élites like an inert organic mass that expands and contracts with resources, ignoring the organizational aspects of hierarchy. A need for organization may raise the proportion of élite administrators regardless of resources, as in the later Roman Empire.

Turchin cites archaeological settlement data from Roman Gaul that display two peaks and troughs. The relationship between the number of archaeological sites and population is complex, as Turchin acknowledges. If this pattern reflects population oscillations, he asserts, then unchecked population growth in the first peak led to insolvency and breakdown. In fact, neither peak reflects simple population growth. The first (from the first to the second century AD) came from Romanization and settlement of veterans, the second (in the fourth century) from changes in taxation.

Quodnonfecerunt historicifecerunt biologi 
— biologists presume to go where historians hesitate. Social theory is a minefield, even for those experienced in it. The quantification of historical patterns is useful and important, and should have a place in historical research. But sophisticated mathematics will not improve naive social theories.

Joseph Tainter is at the Rocky Mountain Research Station, US Department of Agriculture Forest Service, Albuquerque, New Mexico 87102, USA.

\section{Get connected}

\section{Me ++: The Cyborg Self and the Networked City \\ by William J. Mitchell \\ MIT Press: 2003. 312 pp. \$27.95, $£ 18.95$}

\section{Joanne Baker}

We are all cyborg nomads. So argues William J. Mitchell in his new book $\mathrm{Me}++$, in which he explores how our intimate relationships with technology shape both our lives and the environments we build around us. $\mathrm{Me}++$ follows on from two of Mitchell's earlier works, City of Bits and E-topia, which investigated the symbiosis of technology and design.

In $\mathrm{Me}++$, Mitchell describes evocatively how miniaturized and dispersed devices, and entirely dematerialized bits of digital information, fundamentally change the way we sense and relate to the world. This realization raises new questions about how we design everything from clothing to cities. Mitchell's thesis is that ever-shrinking devices will increasingly be carried along with us - becoming part of us - rather than being accessed at fixed points in space.

As we swim in a sea of digital information broadcast as electromagnetic waves, through mobile phones, computers, video screens and speakers, we augment our bodily senses through technology, effectively becoming cyborgs. The clothing, walls, buildings and cities that surround us can be thought of as skins, successive layers through which our senses operate.

According to Mitchell, the roles of these skins should be reconsidered. Microscopic sensors, machines and miniature electronic devices can easily be replicated, distributed and carried. For example, tiny temperature sensors, or digital information systems, might be woven into the threads of clothing, rather than being hung as boxes on walls. By plugging ourselves into extended webs of sensors, we might control our own personal environments and, moreover, generate new fields of interaction within entire communities, even globally.

With great clarity, Mitchell describes how traditional, localized cities developed at sites of accumulation of materials, transport and wealth. The urban structure as we know

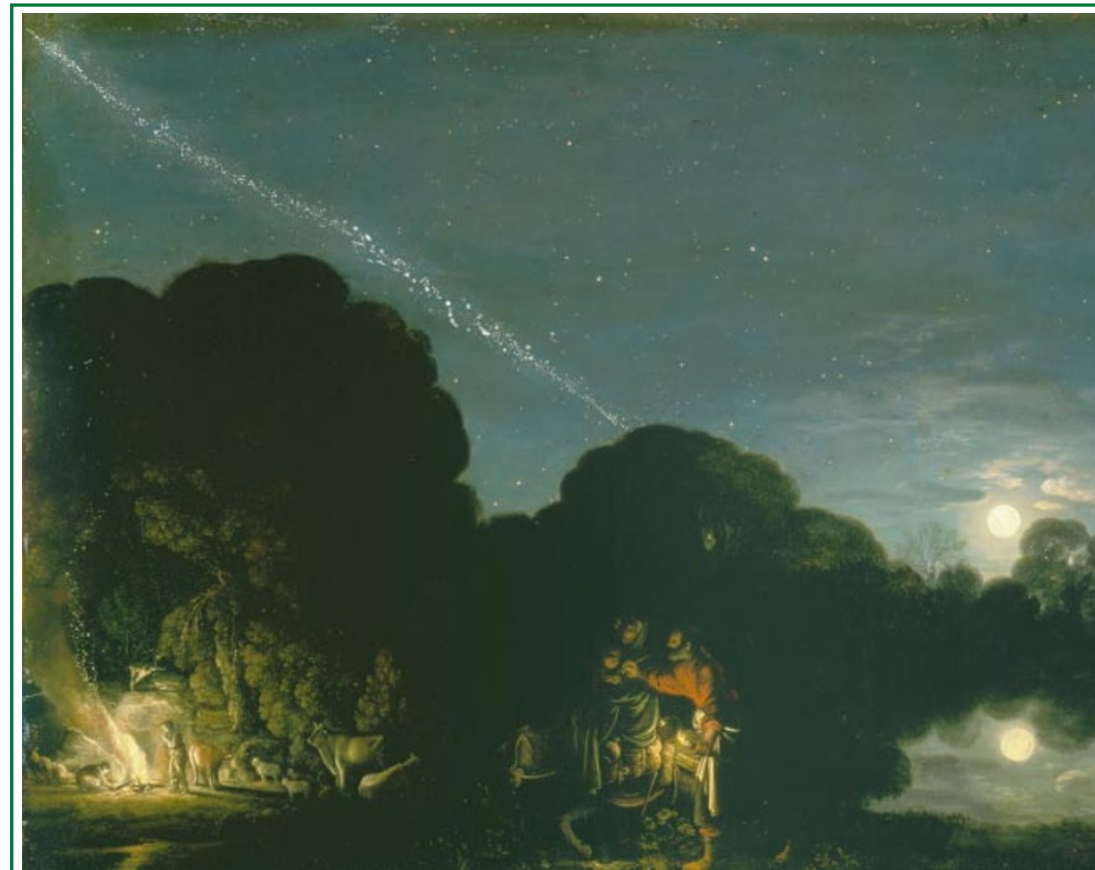

Seeing stars: Adam Elsheimer's Flight into Egypt represents the Milky Way as a series of dots.

\section{Spot the Milky Way}

Ancient Mediterranean civilizations believed that the Milky Way was composed of milk spilled from the breast of a goddess. But when Galileo turned a telescope to the heavens for the first time in 1609, he showed instead that it was made up of untold numbers of individual stars. Adam Elsheimer's Flight into Egypt (above) which was completed in the same year, is the first depiction of the Milky Way in an oil painting.

The painting, which shows the holy family travelling in a scene illuminated by a lowhanging Moon, presents the Milky Way as a series of dots. Does this mean that some people had already understood the true nature of the galaxy, asks Francesco Bertola in his

it - with central business districts, coarse zoning, suburbs and ring roads - follows directly from this function.

But today, the information revolution is changing all that. In Mitchell's view, cities are no longer dominated by localized objects but by dematerialized bits. In a world where you can connect your laptop to the Internet from practically anywhere, location has become incidental, and access to information is the new currency for foraging urban nomads. "I link therefore I am," says Mitchell. Consequently, he argues, urban design should reflect this new dynamic world.

Mitchell concludes provocatively by pronouncing the death of the modernist architectural programme. Form can no longer follow function; spaces should be what we want them to be, when we want them to be. They should be flexible as our needs change. Cafes, parks, hotels and trains can all be tem- sumptuous new book about the Milky Way, Via Lactea (Biblos, €39.95).

The book highlights 60 images that illustrate how artists from across the world, over more than two millennia, have represented the faint celestial arc of the Milky Way. It also includes astronomical pictures taken using groundand space-based telescopes, particularly the Hubble.

The book's text, in English and Italian, describes the myths and legends associated with the Milky Way, as well as its science. But there is also a moral. The Milky Way, inspiration for so much art, philosophy and simple wonder, is no longer visible to most inhabitants of our light-polluted world.

Alison Abbott

porary workspaces for someone with a wireless laptop, so why be confined in a cubicle?

$\mathrm{Me}++$ is an exhilarating read, jampacked with interesting facts, colourful phrases, imagery and sage insights. Some of Mitchell's ideas are not new, but he makes a powerful argument that will influence the designers of our future environment.

Mitchell raises more questions than he answers and leaves the reader wanting more. Big issues of economics, access, surveillance, privacy, security, ownership and identity are mentioned but barely explored. Similarly, there are too few glimpses of the exciting new products that may transform our lives. What form will the futuristic knowledge-based city take? Mitchell articulates the zeitgeist, but even he cannot predict where technology will take us - or where we will take it.

Joanne Baker is in the Department of Physics, Oxford University, Oxford OX1 3RH, UK. 